\title{
Protein-Losing Gastroenteropathy: Concepts Derived from Lymphangiography
}

\author{
Joseph J. Bookstein, M.D., Arthur B. Frengh, M.D., and \\ H. Marvin Pollard, M.D.
}

\begin{abstract}
$I^{N}$
N PROTEIN-LOSING gastroenteropathy, excessive protein loss into the gastrointestinal tract often leads to the clinical syndrome of edema and hypoproteinemia without albuminuria or evidence of liver disease. It may be secondary to a wide variety of diseases including gastric neoplasm. giant hypertrophy of gastric mucosa, ulcerative colitis, regional enteritis, Whipple's disease, and constrictive pericarditis. In a smaller group of patients, the gastrointestinal protein loss is not associated with any of these diseases. For these patients the term "primary protein-losing gastroenteropathy" has been used. Histologic examination of the small intestine in these patients commonly reveals dilated lymphatics in the villi and submucosa. Recognition that an abnormality of lymphatics may be found in protein-losing gastroenteropathy has led to the use of lymphangiography as a diagnostic aid and as an investigative tool to define in more detail the abnormality of abdominal and peripheral lymphatics. The technic appears to have diagnostic usefulness; studies have shown that intestinal lymphangiectasia in these patients is part of a broad spectrum of lymphatic dysplasias. Primary protein-losing gastroenteropathy is in many instances better called "primary intestinal lymphangiectasia," as this disease appears closely related to primary lymphedema. Findings in 2 patients with primary protein-losing gastroenteropathy and 1 with primary lymphedema are presented to support this viewpoint.
\end{abstract}

\section{CASE REPORTS}

\section{Case 1 (protein-losing gastroenteropathy)}

G.F., a 36 -year-old female, had edema of the left foot and leg intermittentiy since 1941. Bilateral lower-extremity edema was noted by 1946 , and in 1948 total serum pro-

From the Departments of Radiology and Internal Medicine (Gastroenterology Section), The University of Michigan Medical School and the Clinical Research Unit of the University of Michigan Hospital, Ann Arbor, Mich.

Supported in part by Grants C9812 from the National Cancer Institute, AM-07120 from the National Institute of Arthritis and Metabolic Diseases, and FR-42 from the Ceneral Clinical Research Centers Branch, Division of Research Facilities and Resources, National Institutes of Health, U. S. Public Health Service.

(9) 1965 by Hoeber Memcal Division - Harper \& Row, Publishers, New York, 
tein levels were found to be low. Sexum protein levels have remained low since that time except during pregnancies and on 2 other isolated occasions. Edema has persisted, however, even when serum proteins have been almost normal. There is usually asymmetry of the edema, with the left leg more swollen than the right.

On admission, Jan. 19, 1964, abnormal physical findings consisted of generalized wild edema involving the face and both legs, but most pronounced in the left leg. Serum protein was $3.1 \mathrm{gm}$. with $2.4 \mathrm{gm}$. of albumin. Fecal fat loss was $5.7 \mathrm{gm}$. per day on an intake of $111 \mathrm{gm}$. daily. Fecal nitrogen was $1.1 \mathrm{gm}$. per day on a protein intake of $112 \mathrm{gm}$. daily. Upper C.I. series, small-bowel, and barim-enema studies were within normal limits. Half-time for disappearance of $118 \mathrm{l}$ albumin from the blood was 2.5 days in November 1963, and 1.5 days in January 1964 (normal, about 12 days) . Peroral small intestinal biopsies at several levels of jejunum revealed villous edema and lymphangiectasis. A lymphangiogram was performed on Feb. 3. After injection of direct sky blue dye,* only a single very small lymphatic channel was seen on the dorsum of the left foot, which could not be successfully cannulated. In the right foot a normal number of lymphatic channels were outlined by the dye, and $15 \mathrm{cc}$. of Ethioflol was in stilled into a dorsal pedal lymphatic. Radiography showed some diminution in the size and number of inguinal and iltac nodes on the right. Pelvic and para-aortic lytr. phatics were normal, but there was marked refux of contrast medium into dilated mesenteric lymph channels (Fig. 1). Hims taken after $24 \mathrm{hr}$. showed opacifacation of multiple small, mottled, mesenteric noles (Fig. 2). The thoracic duct was opacified and appcared normal.

The patient was placed on a low-fat diet (10 gm./day). After eight months on this diet, serum albumin half-disappearance time was 2.0 days, and edcma was unchanged. Fecal fat was $1,8 \mathrm{gm}$. per day on this $10 \mathrm{gm}$. intake. Fecal nitrogen was $1.4 \mathrm{gm}$. on an intake of $89 \mathrm{gm}$. of protein daily.

\section{Case 2 (protein-losing gastroenteropathy)}

S. L., a 74-year-old white male, had a history of intermittent diarrhea for 19 years. intermittent pedal edema for 8 years, and sone exertional dyspnea. A carcinomatous rectal polyp was removed in 1950 . On admission, May 5,1964 , physical examination revealed evidence of pulmonary exphysema. Cardiac findings were normal. The liver edge was palpable $8 \mathrm{~cm}$. below the right costal margin. There was moderate bilateral pitting ankle edema. Tuberculin test was positive. Chest $\mathrm{X}$-ray showed evidence of emphysema and diffuse postinflamuatory scarring. Gastrointestinal $\mathrm{X}$-rays were normal. Serum proteins were $4.9,6.8$, and $6.6 \mathrm{gm} . / 100 \mathrm{ml}$. in December 1963 , and 7.4 in May 1964. Serum albumins were 2.2. 4.5, and $4.7 \mathrm{gin} . / 100 \mathrm{ml}$. in December, and 4.2 in May. Edema decreased with the rise in serum albumin but did not disappear conpletely. On electrophoretic analysis, $66 \%$ of the total protein was albumin; of the globulins, $8 \%$ was alpha-1; $4 \%$, alpha-2; $8 \%$, bcta; and 19\%, gamma. In December 1963, fecal fat lossts were $3.1 \mathrm{gm}$. per day with an intake of $66 \mathrm{gm}$. per day, and $3.9 \mathrm{gm}$. per day on an intake of 94 gm. per day. Fcol nitrogen losses were $1.5 \mathrm{gm}$. per day on a protein intake of $75 \mathrm{gm}$, and $1.5 \mathrm{gm}$. per day on an 83-gm. protein intake. Seyeral attempts at small-bowel biopsy were unsuccessful. Serum albumin half-disappearance time was 3 days. I.ymphangiograms revealed hilateral hypoplasia of the lymphatic channels of the lower extremities. The abdominal lymph channels and nodes appeared

*blained from Wyeth Laboratories, Philadelphia, $p_{\text {at. }}$

+ E. Fougera \& Co., Hicksville, N. Y. 
normal. The cisterna chyli was chlarged (Eig. 3); instead of clearing promptly, it remained opacifed for over $48 \mathrm{hr}$. The thoracic duct appeared normal.

In May 1964, the patient was given a low-fat diet in the hope of reducing albumin loss into the intestinal lumen. Edema did not improve. Serum albumin half-disappeaxance time was 2 days. In September 1964 , serum protein was $6.2 \mathrm{gm} . / 100 \mathrm{ml}$, with 3.8 gma albumin. So that the effect of dietary fat on albumin turnover could be evaluated, the patient was given a high-fat diet. Abdominal discomfort increased and there was mild diarrhea. Edema was unchanged. Fecal fat was 10.4 and $9.8 \mathrm{gm}$. per day on a $125 \mathrm{gm}$. intake. Fecal nitrogen was 1.7 and $1.7 \mathrm{gm}$. per day, fecal sodium losses were mildly increased to 23 and $35 \mathrm{mEq}$. per day, and fecal potassium losses were also increased to 92 and $97 \mathrm{mEq}$. per day. Serum albmin half-disappearance time remained 2 days.

\section{Case 3 (primary lymphedema)}

W. B., a 20 -year-old white male, had had intermittent swelling of the left leg for the past 10 years. The swelling began following mild trauma. The right leg began to swell I year later and marked swelling of both lower extremities had persisted since that time.

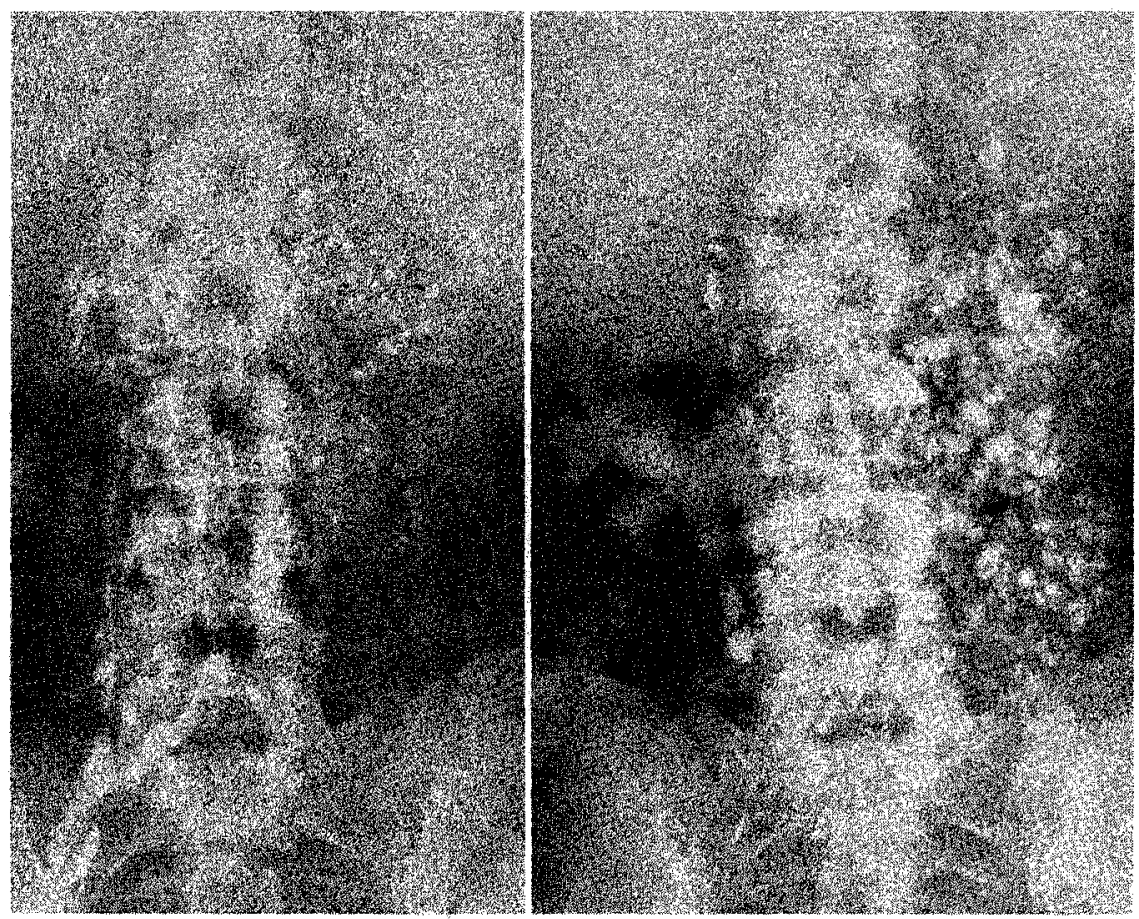

Fig. 1 (lef6). In primary protein-losing gastroenteropathy (Case 1), lymphangiogram, lymphatic phase, shows marked reffux into numerous dilated mescnteric lymph channels. Fig. 2 (right). Lymphangiogram, lymph node phase, in same case as Fig. 1, showing opacification of large numbers of mottled mesenteric Iymph nodes. 
Physical examination findings were unremarkable except for edema of both lower extremities with marked thickening of the skin. Results of laboratory studies werc normal, including normal total serum-protein levels and albumin:globulin ratio. An upper G.I. series was normal.

Lymphangiograms (Fig. 4) showed dermal backfow in the left lower extremity without evidence of other Iymphatic abnormality in that extremity. The right side was not injected. Collateral lymphatic channels passed from the left inguinal nodes along the flanks, and there was reflux into varicose right pelvic lymph channels. Left pelvic channels were similarly dilated and tortuous. Para-aortic channcls and thoracic duct were not seen. Subsequent films showed opacification of lymph nodes of the mesentery and porta hepatis (Fig. 5).

\section{DISCUSSION}

As recently as 1949 , when "idiopathic hypoproteinemia" was the current term, Albright et al. ${ }^{1}$ first showed that infused human serum albumin disappeared from the blood stream and appeared in the urine as non. protein nitrogen more rapidly in these patients than in normals. Kinsell2 then showed that the rate of synthesis of albumin from $S^{85}$ albumin was normal, and confirmed the rapid turnover of the albumin which was synthesized. Albumin tumovers in these patients were comparable to the 1.8- to 2.3-day half-times observed in nephrotic children by Gitlin et al." At this point it became more logical to use the term "hypercatabolic hy. poproteinemia," first applied by Schwartz and Thomsen." It was recog. nized that albumin breakdown was increased and that nitrogenous breakdown products were excreted in urine. It had not yet been shown

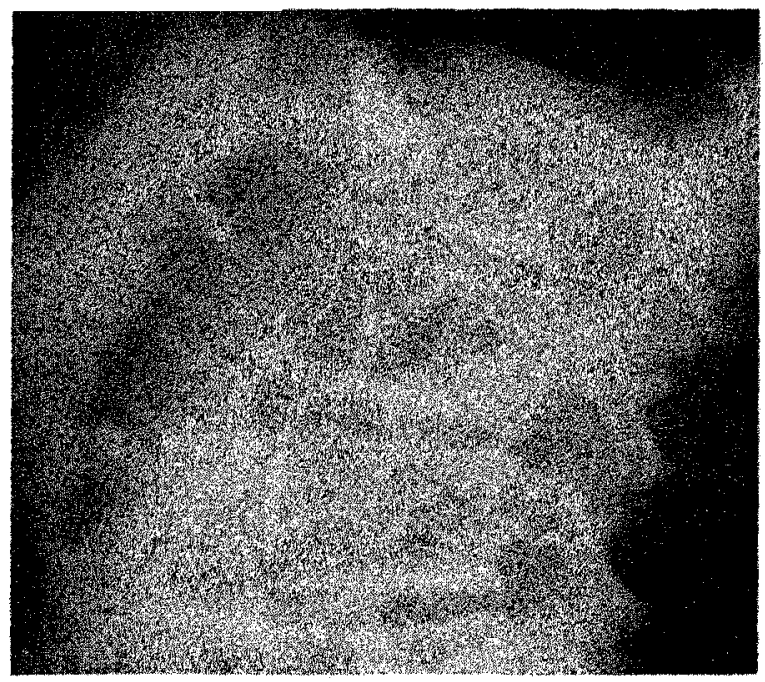

Fig. 3. In primary proteinlosing gastroen teropathy (Cas: 2), Iymphangiogram, 24.hr. film, shows some enlargement of cisterna chyli and pro. longed opacification. Similat opacification was present at $48 \mathrm{hr}$. 
that the hypercatabolism of albumin was due to loss into the gastrointestinal tract, digestion of the albumin, reabsorption of amino acid, and excretion of metabolic products of amino-acid catabolism in urine. In 1957, Steinfeld et $a l .5^{5}$ by recovering $\mathrm{I}^{131}$-albumin from feces, showed such loss into the gastrointestinal tract in patients with regional enteritis and ulcerative colitis. In the same year Citrin et al. ${ }^{6}$ recovered ${ }^{131}$-albumin from the stomachs of patients with giant hypertrophic gastritis. With Gordon's introduction of $\mathbf{I}^{131}$ polyvinylpyrollidone (PVP), it was found that similar loss of large molecules through the intestinal wall occurs with many infiltrative diseases of the gastrointestinal tract. Similar PVP losses were seen in patients without well-defined gastrointestinal disease. These patients were then said by Gordon to have "exudative enteropathy," although the cause of the "exudation" was unclear. The more precise term

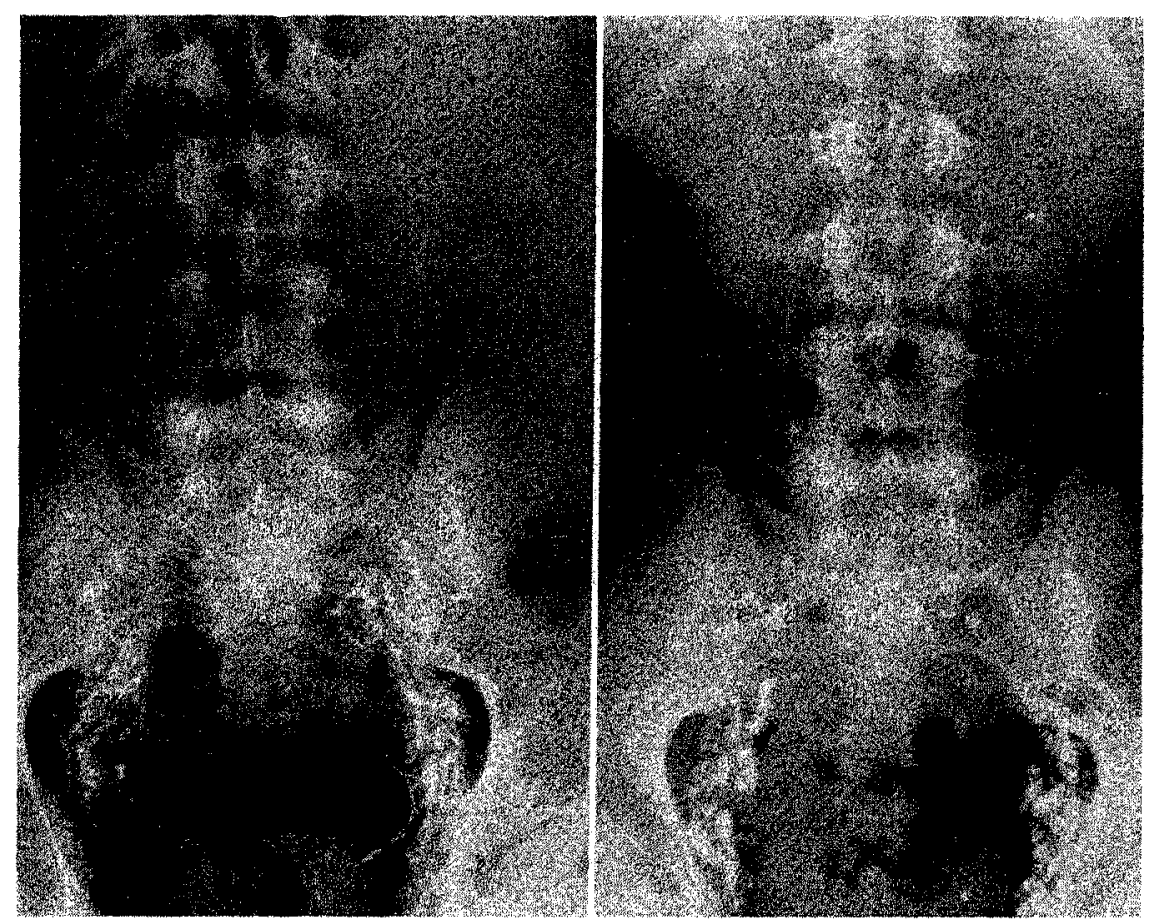

Fig. 4 (left). In primary lymphedema (Case 3), lymphangiogram of left side, lymphatic phase, shows varicose lymphatic vessels within pelvis, Marked reflux has occurred from left lliac channels into right channels. Left flank collaterals, present on original films, are not shown. Note virtual absence of opacification of para-aortic channels at this time. Fig. 5 (right). In same case as Fig. $4,24-\mathrm{hr}$, film shows opacification of multiple small mottled lymph nodes thought to lie within mesentery and porta hepatis. 
"protein-losing gastroenteropathy" has been more widely accepted. often designated "primary" or "secondary" to indicate the presence or absence of other underlying disease. In 1961, Waldman et al. ${ }^{8}$ described lymphangiectasia in the intestinal villi in 12 of 20 patients with idiopathic hypo proteinemia, and it has been confirmed that most cases of primary protein-losing gastroenteropathy actually are the result of intestinal lymphangiectasia.

In 1963 Pomerantz and Waldman' reported the use of lymphangiography in 4 cases of intestinal lymphagiectasia. Hypoplastic lower-extremity lymphatics were present in 3 patients, 1 of whom demonstrated dermal backflow. In a fourth patient, there was virtual aplasia of pelvic and retroperitoneal lymph nodes, despite apparently normal lymphatic chan nels. The possibility of obstruction of the thoracic duct was suggested in 1 case.

Mistilis et al. ${ }^{10}$ reported 1 case with varicose lymphatics of the lower extremity, reflux into strikingly dilated mesenteric and intestinal lymphatics, and extravasation of opacified lymph into the duodenal lumen. Partial obstruction of the lower thoracic duct was also suspected: This patient had gross steatorrhea (24. gm. per day); Waldman's patients lost $5-8.5 \mathrm{gm}$. of fecal fat per day, and ours lost $3.1-10.4 \mathrm{gm}$. per day on normal intakes. In Mistilis' patient, lymphangiographic contrast medium outlined the duodenal lumen. In this case, extravasation of lymph into the duodenum from rupture of lymphatics might explain the steatorrhea. This would be comparable to findings of extravasation of lymph into body cavities in chyluria, chylothorax, and chylous ascites. ${ }^{11}$

Both of our patients demonstrated hypoplasia of lower-extremity lymphatics. In one, marked reflux into dilated mesenteric lymphatics was seen, while in the other, the cisterna chyli was dilated and retained contrast medium longer than usual. In neither case was contrast medium identified within the intestinal lumen. Thus, all 3 reports of lymphangiographic studies in patients with protein-losing gastroenteropathy em. phasize abnormalities of both lowerextremicy and abdominal lymphatics.

Kinmonth et al., ${ }^{12}$ in a lymphangiographic study of 107 patients with primary lymphedema, found that approximately $70 \%$ of the patients had hypoplasia or aplasia of peripheral lymphatics, and $24 \%$ had lymphatic varicosities. Only lower-extremity lymphangiograms were described. The report gave no evidence that abdominal lymphatics were examined. The cases described by Pomerant $z$ and Waldman ${ }^{9}$ and by Mistilis et al., ${ }^{10}$ and those presented above, show very comparable abnormalities of peripheral lymphatics, in addition to abnormal abdominal lymphatics in some. Certain speculations seem justified: Are congenital lymphedema and pri- 
mary protein-losing gastroenteropathy merely divergent manifestations of a similar lymphatic dysplasia? Does protein-losing gastroenteropathy simply reflect greater abnormality of intestinal lymphatics, while pri. mary lymphedema results from predominant dysplasia of peripheral lymphatics? Stoelinga et al. ${ }^{13}$ postulated this relationship without benefit of lymphangiography. Their patient with protein-losing gastroenteropathy had a sister with lymphedema of unknown type whose $\mathrm{Cr}^{\text {s. }}$ loss in the stools was normal.

Do some patients with primary lymphedema have abnomalities of abdominal lymphatics and lose excessive protein into the gastrointestinal tract? Waldman't1 implies that they do not, since he used patients with primary lymphedema as controls in his study of fecal losses of $\mathrm{Cr}^{\text {th }}$ albumin. We have not yet had the opportunity to study intestinal protein loss in primary lymphedema. However, in 1 incompletely studied case (Case 3), on lymphangiography there was reflux of contrast medium into varicose pelvic lymphatics and mesenteric lymph nodes, demonstrating that lymphatic dysplasia in primary lymphedema is not always confined to the legs, and suggesting that on closer study, some patients thought to have primary lymphedema may demonstrate varying degrees of gastrointestinal protein loss.

The lymphatic abnomality in patients with intestinal lymphangiectasia is clearly shown to be generalized, but its origin is not yet understood. The variety of lesions which have been seen suggests congenital dysplasia of the lymphatics, at least of the lower extremities and abdomen, and perhaps more widespread. One can postulate that when the dysplasia approaches aplasia, lymphatic drainage is inadequate from birth and edema appears early. The clinical picture is that of primary lymphedema. When dysplasia is milder, edema may develop only when additional factors, such as lowered serum osmotic pressure due to loss of albumin, lead to increased extravasation of fluid in the dependent extremity. This would represent primary protein-losing gastroenteropathy. Edema in such patients would be milder and more intermittent. This picture would be more common when the congenital abnormality involves the thoracic duct or cysterna chyli. However, in both of our cases and in 2 of Waldman's, ${ }^{9}$ the thoracic duct was apparently normal. Since Pomerantz. et al. ${ }^{15}$ did not find reflux into intestinal lymphatics after thoracic-duct ligation, it seems likely that functional or anatomic dysplasia of intestinal lymph vessels rather than anatomic obstruction of the thoracic duct is the underlying cause of most cases of "primary" intestinal lymphangiectasia.

The diagnosis of intestinal lymphangiectasia may be of more than academic interest. Jeffries ef al. ${ }^{16}$ found that 2 patients with protein-los- 
ing gastroenteropathy were helped by low-fat diets ( $5 \mathrm{gm}$./day). Serum protein rose and albumin turnover time increased. Lymphangiograms were not reported. In our patients who were treated with low-fat diets (10 gm./day), edema and albumin turnover rate remained unchanged. The patient of Stoelinga et al. ${ }^{13}$ improved symptomatically on a fat-free (2-4 gm, diet, but edema was unchanged. Our patients showed considerable involvement of peripheral lymphatics; although hypoalbuminemia was intermittently present, edema persisted at times when serum-albumin concentrations were normal. This may have reflected peripheral lymphatic insufficiency. Jeffries et al ${ }^{16}$ postulated that a low-fat diet reduced the volume of chyle transported by the inadequate intestinal lymphatics, with consequent diminished lymph pressure and protein loss. It seens reasonable to suppose that such therapy will not effectively reduce peripheral edema in patients witl major insufficiency of peripheral lymphatics. Thus, further study may show the lymphangiogram to be useful in predicting whether peripheral edema will respond to the low fat regimen.

\section{SUMMARY}

Lymphangiograms in 2 patients with protein-losing gastroenteropathy showed abnormalities of both abdominal and lowerextremity lymptiatics.

With the application of lymphangiography, the generalized nature of the lymphatic dysplasia in primary protein-losing gastroenteropathy has become evident.

Striking lymphangiographic similarities between primary protein-losing gastroenteropathy and primary lymphedema suggest that both entities are part of a continuous spectrum of lymphatic dysplasias.

A. B. F.

University Hospital Ann dibor, Mich.

\section{REFERENCES}

1. Albrighr, F., Bartrer, F. C., and Formes, A. P. The fate of human serum albumin administered intravenously to a patient with idiopachic hypoalbuminemia and hypoglobulinemia: Tr. A. Am. Physicians 62:204, 1949.

2. Kinglex, I. W. Marcen, S., Tarver, H., Frantz, J. McB., Flanagan, E. K, Hunchiv, M. D. Mchaels, G. D.s and McCalle, D. P. Studies in methionine metabolism. II. The fate of intravenously administered $\mathrm{S} 9 \mathrm{~s}$ labeled methionine in normal adult males, in patients with chronic hepatic discase, "idiopathic hypoproteinemia," and Cushing"s Discase, J. Clin.fwest. $29: 298,1950$.

3. Griun, D., JANfwar, C. A, and FARr, I. F. Studies on the metabolism of plasma proteins in the nephrotic syndrone $I$ albumin, and globulin and iron binding globulin. J. Clin. Invest. 35:44, 1956.

4. Schwartz, M., and Thonsen, B. ldiopathic or hypercatabolic bypoproteinemia. Bnt, $M, J, 1: 14,1957$.

5. Strinferd, J. L., Davidson, J. D., and Gordox, R. S. A mechanism for hypoalbu. 
minemia in patients with ulcerative colitis and regional entcritis. J. Chin. Invest. $36: 931,1957$.

6. Citrin, Y., Sterlane, K., and Haistead, J. A. The mechanism of hypoprotenemia associated with giant hypertrophy of the gastric mucosa, N. England J. Med. 257: 906,1957 .

7. Gordon, R. S. Exudative enteropathy, abnormal permeability of the gastrointestinal tract demonstrable with labelled polyvinylpyrrolidone. Lancet $1: 325,1959$.

8. Waldman, T. A., Steinefld, J. L., Detcher, T. F., Davidson, J. D., and Gordon, R. S. The role of the gastrointestinal system in "idiopathic hypoproteinemia." Gastroenterology 41:197, 1961.

9. Pomerantz, M., and Walmman, T. A. Systemic lymphatic abnormalities associated with gastrointestinal protein loss secondary to intestinal lymphangicctasia. Gastroenterology 45:708, 1963 .

10. Mistilis, S. P., Skiring. A. P., and Steriens, D. D. Intestinal lymphangiectasia mechanism of enteric loss of plasma, protein and fat. Lancel 1:77, 1965.

11. Whluace, S., Jackson, L., Dond, G. D., and Grefning, R. R. Lymphatic dynamics in certain abnormal states. Am. J. Roentgenol. 91:1187, 1964.

12. Kinmonth, J. B., Taylok, G. W., Tracy, G. D., and Marsh, J. D. Primary lymph. edema: Clinical and lymphangiographic studies of a series of 107 patients in which the lower limbs were affected. Brit. J. Surg. 15:1, 1957.

13. Stoflmga, G. B. A., van Munster, P. J. J.. and Sloof, J. P. Chylous effusions into the intestine in a patient with protein losing gastroenteropathy. Pediatrics 31:1011, 1963.

14. Waldman, T. A. Gastrointestinal protein loss demonstrated by Cras labelled albumin. Lancet 2:121, 1961 .

15. Pomerantz, M., Herdt, J. R. L., Rockofr, S. D, and Kercham, A. S. Evaluation of the functional anatomy of the thoracic duct by lymphangiography. J. Thoracic Cardiovasc. Surg. 46:568, 1963.

16. Jffrries, G. H., Chapman, A. and Sulsenger, M. H. Low fat diet in intestinal lymphangiectasia. N. Fngland J. Med. 270.761, 1964. 